\title{
Special issue: Twelfth Workshop on Models and Algorithms for Planning and Scheduling Problems (MAPSP 2015)
}

\author{
Yves Crama $^{1}$ - Dries Goossens ${ }^{2} \cdot$ Roel Leus $^{3} \cdot$ Michaël Schyns $^{1} \cdot$ Frits Spieksma $^{3}$
}

Published online: 10 November 2017

(C) Springer Science+Business Media, LLC 2017

This special issue of the Journal of Scheduling contains ten papers presented at the Twelfth Workshop on Models and Algorithms for Planning and Scheduling Problems (MAPSP 2015), held from June 8 to June 12, 2015, in La Roche-enArdenne, Belgium.

MAPSP is a biennial workshop dedicated to all theoretical and practical aspects of scheduling, planning, and timetabling. Previous MAPSP meetings have been held in Menaggio, Italy (1993), Wernigerode, Germany (1995), Cambridge, UK (1997), Renesse, Netherlands (1999), Aussois, France (2001), Aussois, France (2003), Siena, Italy (2005), Istanbul, Turkey (2007), Kerkrade, Netherlands (2009), Nymburk, Czech Republic (2011), and Pont à Mousson, France (2013).

The twelfth edition of the workshop featured invited talks by Onno Boxma (TU Eindhoven), Michel Goemans (MIT), Rolf Niedermeier (TU Berlin), Willem-Jan Van Hoeve (Carnegie-Mellon University), and Stephan West-

$\triangle$ Yves Crama

Yves.Crama@ulg.ac.be

Dries Goossens

Dries.Goossens@ugent.be

Roel Leus

Roel.Leus@kuleuven.be

Michaël Schyns

M.Schyns@ulg.ac.be

Frits Spieksma

Frits.Spieksma@kuleuven.be

1 HEC Liège - Management School, University of Liège, rue Louvrex 14, 4000 Liège, Belgium

2 Faculty of Economics and Business Administration, Ghent University, Tweekerkenstraat 2, 9000 Ghent, Belgium

3 Faculty of Economics and Business, KU Leuven, Naamsestraat 69, 3000 Louvain, Belgium phal (TU Clausthal), as well as 88 contributed talks. Each submission was reviewed by at least three program committee members. The booklet of abstracts and additional information about the workshop are available at http://www. mapsp2015.com/.

All participants in the conference were subsequently invited to submit a paper for this special issue of Journal of Scheduling. The submissions have undergone the usual reviewing process of the journal, so as to ensure the highest quality for the issue. The outcome of this demanding process is to be found in the next pages.

We owe a lot of thanks to various organizations and colleagues. The organization of the workshop MAPSP 2015 was supported by KU Leuven, the University of Liège, Ghent University, the Belgian Science Policy Office (under IAP project P7/36 COMEX), the Belgian Society for Operations Research (ORBEL), and the companies N-SIDE, OMPARTNERS, and ORTEC. Our colleague Alberto MarchettiSpaccamela (Sapienza Università di Roma) was Chair of the Program Committee of the workshop and, together with the other members of the committee, was largely responsible for the quality of its scientific program. Edmund Burke, Editorin-chief of the Journal of Scheduling, accepted our proposal to edit a special issue of the journal and has supervised the editorial process. Numerous referees have done a fantastic job in providing high-quality reviews of the submitted papers, sometimes under tight deadlines! Our gratitude extends to all of them. 